\title{
Experimental determination of fuel evaporation rates using IR-Thermography
}

\author{
by M. Founti ${ }^{1}$, D. Kolaitis ${ }^{1}$, G. Zannis ${ }^{1}$, O. Kastner² D. Trimis ${ }^{2}$ \\ (1) Laboratory of Heterogeneous Mixtures and Combustion Systems, Thermal Engineering \\ Section, Mechanical Engineering Department, National Technical University of Athens, \\ Heroon Polytechniou 9, Polytechnioupoli Zografou, 15780 Athens, GREECE \\ Tel: +30-10-7723605, Fax: +30-10-7723663, e-mail: mfou@central.ntua.gr \\ (2) Lehrstuhl für Strömungsmechanik, Universität Erlangen-Nürnberg, \\ Cauerstrasse 4, D-91058 Erlangen, GERMANY \\ Tel.: +49 (0) 9131 852-9490, Fax: +49 (0) 9131 852-9503, \\ e-mail: dimos@/stm.uni-erlangen.de
}

\begin{abstract}
The scope of the present work is to experimentally investigate the heat and mass transfer phenomena occurring in the case of pure liquid as well as FAME-diesel fuel mixture droplets evaporating in a constant temperature and constant air velocity environment. Experiments have been performed to record the time evolution of droplet diameter and surface temperature. An ultrasonic droplet acoustic levitator has been operated in order to suspend the isolated droplets in air. A fast CCD camera and an infrared camera have been used to record droplet diameters and droplet surface temperatures, respectively. The produced experimental data can be used in the validation of computational and empirical models for single, pure liquid or multicomponent droplet evaporation.
\end{abstract}

\section{Introduction}

Oil fired furnaces and boilers, diesel engines and gas turbines utilize liquid fuel sprays in order to increase the fuel surface area and thus accelerate the vaporization and combustion rates. Conventional technologies, used to burn a liquid fuel, inject the fuel into the combustion chamber through a nozzle that atomises it, producing a spray comprising a large number of droplets, typically of the order of a few tens of micron to a few hundreds of micron in diameter. The droplets, subjected to the high temperatures of the combustion chamber, are evaporated and burnt in a sequential process. In order to study and examine the evaporation behaviour of a spray, one can focus on a single droplet, evaporating in a convective environment. Study of such a case may yield invaluable information for the modelling of the evaporation process.

The scope of the present work was to experimentally investigate the heat and mass transfer phenomena occurring in the case of a droplet evaporating in a constant temperature and constant velocity air environment, aiming to the creation of an experimental database useful for the computational modelling of the evaporation process. The experimental device used was an acoustic levitator, which is a valuable tool in order to study the heat and mass transfer phenomena occurring at the surface of an evaporating droplet, since it allows an almost steady "hanging" of the droplet without any mechanical supports.

Examined fuels included both pure liquids (decane, ethanol and $n$-heptane) as well as multicomponent mixtures, consisting of industrial diesel oil (type EL) - FAME (Fatty acid methyl ester) blends. The commercial use of such mixtures (containing FAME up to $20 \%$ per volume) is expected to raise in the near future, since FAME are considered renewable energy sources and there is a worldwide trend towards the extension of the application of such fuels. 


\section{Experimental set-up}

The experimental investigations of the single droplet evaporating phenomena were carried out at the Lehrstuhl fuer Stroemungsmechanik, University of Erlangen, Germany, with the use of an in-house developed acoustic levitation device [1]. A photograph of the test rig is shown in Figure 1a. The substances investigated were pure liquid fuels (such as decane, ethanol, $n$-heptane) and mixtures of diesel oil with various kinds of biodiesel (such as AME - used frying oil methyl ester and RME - rape seed methyl ester). The ambient air mean temperature was kept at a moderate $\left(80-94^{\circ} \mathrm{C}\right)$ level.

The acoustic levitator employed a transducer, which was connected to an oscillating piezocrystal that transmitted oscillations to the surrounding air. This resulted to the emergence of a standing wave between the transducer and a porous reflector positioned at the top of the device. The whole system (piezocrystal and reflector) had been embedded in a glass tube. The droplet to be examined was positioned near the pressure nodes of the created standing wave. The glass tube allowed better control of droplet stability, air temperature, relative humidity and mass flow around the droplet. A stream of ventilating air, entering the tube levitator through a small ring slot and leaving through a top porous reflector, was used to remove the produced fuel vapours, in order to keep the droplet in a pure air environment. As a result, a slightly forced convection environment was created. An electrical heating device, located upstream of the test section, controlled the air temperature.

Table 1: Operational conditions for all experimental test cases

\begin{tabular}{|c|c|c|c|c|c|c|}
\hline $\begin{array}{c}\text { Test } \\
\text { case }\end{array}$ & Fuel & $\begin{array}{c}\text { Liquid } \\
\text { surface } \\
\text { tension } \\
{[\mathrm{mN} / \mathrm{m}]}\end{array}$ & $\begin{array}{c}\text { Initial } \\
\text { droplet } \\
\text { diameter } \\
{[\mathrm{mm}]}\end{array}$ & $\begin{array}{c}\text { Initial } \\
\text { droplet } \\
\text { temperature } \\
{\left[{ }^{\circ} \mathrm{C}\right]}\end{array}$ & $\begin{array}{c}\text { Convective } \\
\text { airstream } \\
\text { temperature } \\
{\left[{ }^{\circ} \mathrm{C}\right]}\end{array}$ & $\begin{array}{c}\text { Calculated } \\
\text { airstream } \\
\text { velocity } \\
\text { [m/s] }\end{array}$ \\
\hline 1.1 & Decane & 14.708 & 1.137 & 73.8 & 94 & - \\
\hline 1.2 & Ethanol & 14.708 & 1.261 & 34.2 & 94 & - \\
\hline 1.3 & n-Heptane & 19.256 & 1.422 & 15.5 & 24 & 0.146 \\
\hline 1.4 & n-Heptane & 13.307 & 1.159 & 49.0 & 94 & 0.091 \\
\hline 2.1 & $\begin{array}{c}5 \% \text { AME }- \\
95 \% \text { Diesel }\end{array}$ & 27.9 & 1.188 & 70.3 & 94 & 0.255 \\
\hline 2.2 & $\begin{array}{c}20 \% \text { AME }- \\
80 \% \text { Diesel }\end{array}$ & 28.2 & 1.218 & 71.2 & 94 & 0.321 \\
\hline 2.3 & $\begin{array}{c}5 \% \text { RME }- \\
95 \% \text { Diesel }\end{array}$ & 28.0 & 1.210 & 72.6 & 92 & 0.261 \\
\hline 2.4 & $\begin{array}{c}20 \% \text { RME }- \\
80 \% \text { Diesel }\end{array}$ & 28.2 & 1.212 & 61.5 & 80 & 0.359 \\
\hline
\end{tabular}

In order to keep record of the temporal evolution of the droplet diameter and temperature, a CCD camera (HITACHI, 680*520 pixels) and an infrared thermal camera (FLIR Thermacam PM595) have been used, respectively. To achieve a direct optical access between the droplet and the thermal camera, a hole - with a diameter of $4 \mathrm{~mm}$, sufficiently small in order to have the minimum interference to the flow field - has been drilled in the glass tube. The thermal camera was operated at a temperature range $-40^{\circ} \mathrm{C}$ $\sim+120^{\circ} \mathrm{C}$. A typical thermogram of a methanol droplet, evaporating in an airstream of 
$24^{\circ} \mathrm{C}$ is shown in Figure $1 \mathrm{~b}$. Emissivity factors for the various tested fuels were estimated by calibrating the camera with the use of a thermocouple. Sources of measurement inaccuracy can be associated with slight movement of the suspended droplets, background radiation from the hot inner surface of the glass tube enclosing the droplets and from the estimation of the emissivity factors.

The measurement accuracy of the thermal camera is $\pm 2 \%$ and its thermal sensitivity is less than $0.1 \mathrm{~K}$. Its detector consists of $320 \times 240$ pixels, while its spectral range is $7.5-13$ $\mu \mathrm{m}$. The sampling rate of the camera in the used configuration was 1 thermograph/sec. Thermal data were processed using the commercial software "ThermaCAM Researcher 2001", which is capable to estimate the surface temperature of the viewed object, taking into consideration the emissivity of the object, the distance between the object and the camera and the conditions of the ambient environment (temperature, relative humidity).

The air-stream flowing inside the levitator was used to remove the fuel vapour. The convective environment surrounding the droplet was created by the vortices induced by the acoustic field. In order to determine the air-droplet relative velocity, i.e. the air-stream velocity since the droplet remained virtually stationery, a semi-empirical correlation was used, taking into consideration the possible depletion of the acoustically induced vortex system by the ventilation airstream [2]. In the first two test cases, this velocity was found to be negligible, thus these test cases refer actually to a free convection problem (zero slip velocity condition). The major operational parameters for the test cases that have been experimentally investigated are reported in Table 1.

\section{Results}

Diagrams of the time evolution of the droplet diameter as well as surface temperature have been produced. The values of the droplet diameter were calculated using the photographic snapshots taken by the CCD camera, while the droplet surface temperature temporal profiles have been estimated, using the information given by the infrared photographs taken by the thermal camera. The two cameras were synchronized by using the internal clock of the thermal camera.

\subsection{Pure Liquids}

In the first case examined, a decane droplet, having an initial diameter of $1.137 \mathrm{~mm}$ and an initial temperature of $73.8^{\circ} \mathrm{C}$, was evaporated in a quiescent air environment of $94^{\circ} \mathrm{C}$. In Figure $2 \mathrm{a}$ the temporal evolution of the squared diameter and the surface temperature of the droplet are depicted. The experimental data show a monotonous increase of the droplet temperature and a nearly linear decrease of the squared droplet diameter. This is consistent with the theoretically expected steady-state evaporating behaviour of a pure distillate fuel droplet, since the so-called " $d^{2}$-law" [3] suggests that the plot of droplet diameter squared versus time is approximately linear.

In the second test case, the droplet that is evaporating in the $94^{\circ} \mathrm{C}$ quiescent air environment is an ethanol droplet, with an initial diameter of $1.261 \mathrm{~mm}$ and an initial temperature of $34.2^{\circ} \mathrm{C}$. Figure $2 \mathrm{~b}$ shows how both droplet squared diameter and surface temperature are varying with time. At the last measuring time-point $(t=50 \mathrm{sec})$, the droplet temperature seems to increase rapidly, even above $78^{\circ} \mathrm{C}$, which is ethanol's boiling point temperature. This discrepancy can be attributed to the rather small droplet size that results to droplet unsteadiness and oscillations inside the acoustic levitator. Thus, the measured temperature is not considered accurate anymore.

The third test case, which can be seen in Figure 3a, refers to an n-heptane droplet of $1.422 \mathrm{~mm}$ initial diameter and $15.5^{\circ} \mathrm{C}$ initial temperature, evaporating in a convective air environment of $24^{\circ} \mathrm{C}$. In this case, the aforementioned semi-empirical correlation has been used in order to determine the air velocity magnitude $\left(u_{\text {air }}=0.146 \mathrm{~m} / \mathrm{s}\right)$. Also here, the squared diameter of the droplet decreases almost linearly with time. 
The temporal evolution of the evaporation behaviour of an $\mathrm{n}$-heptane droplet with initial diameter of $1.159 \mathrm{~mm}$ and initial temperature of $49.0^{\circ} \mathrm{C}$, subjected to a convective air environment $\left(u_{\text {air }}=0.091 \mathrm{~m} / \mathrm{s}\right)$ of $94^{\circ} \mathrm{C}$, can be seen in Figure $3 \mathrm{~b}$. The experimental data suggest that the droplet's temperature increases continuously, remaining in any case under the "boundary" of $98^{\circ} \mathrm{C}$ that represents n-heptane's boiling temperature. It is worth noting that compared to the previous test case, while the general form of both diameter and temperature curve remains the same, the droplet total evaporation time is reduced almost by a factor of 4 .

\subsection{Diesel-FAME Mixtures}

There are various complications that occur when a multi-component liquid is considered. Different components vaporize at different rates, creating concentration gradients in the liquid phase resulting in liquid-phase mass diffusion. At first, the more volatile substances tend to vaporize faster at first until their surface concentrations values are diminished and further vaporization of those quantities becomes liquid-phase-massdiffusion controlled [4].

In Figure 4a, squared droplet diameter and droplet surface temperature temporal profiles of a droplet consisted of $5 \%$ AME-95\% Diesel oil, evaporating in a convective air environment of $94^{\circ} \mathrm{C}$ are depicted. The droplet has an initial temperature of $70.3^{\circ} \mathrm{C}$ and an initial diameter of $1.188 \mathrm{~mm}$. A region of droplet diameter increase is observed during the first stage of the evaporation. This is attributed to the fact that, in this case the expansion due to heating is greater than the mass loss due to evaporation [3]. Nevertheless, after the first $150 \mathrm{sec}$, the squared droplet diameter curve resumes its rather linear shape.

In Figure 4b, the mixture composition becomes 20\% AME-80\% Diesel oil. The droplet, $\left(D_{p, 0}=1.218 \mathrm{~mm}, T_{p, 0}=71.2^{\circ} \mathrm{C}\right)$ is subjected to an airstream of $94^{\circ} \mathrm{C}$. In this case, the evaporation rate is slightly more intense, suggesting that the addition of AME results to a decrease of the total droplet evaporation time. At $600 \mathrm{sec}$, a sharp drop in both diameter and temperature is observed. This is attributed to a droplet oscillation inside the acoustic levitator, since in this case, it could not be achieved a fully stable droplet positioning. However, the droplet "resumes" its normal evaporating behaviour after just $10 \mathrm{sec}$, therefore the above measurement region should be neglected.

The evaporation behaviour of a multicomponent (5\% RME - 95\% Diesel) droplet $\left(D_{p, 0}=1.210 \mathrm{~mm}, T_{p, 0}=72.6^{\circ} \mathrm{C}\right)$ which is subjected to a heated airstream of $92^{\circ} \mathrm{C}$ can be seen in Figure $5 a$. Since also in this case it was not possible to keep the droplet in a steady position, a sharp drop of both diameter and temperature is being observed near the $300 \mathrm{sec}$ and the $870 \mathrm{sec}$ time-points. This is again owed to acoustically induced droplet oscillations and should not be taken into account.

Finally, in Figure $5 b$ the temporal evolution of a multicomponent $(20 \%$ RME $-80 \%$ Diesel) droplet's diameter and surface temperature, evaporating in a heated airstream of $80^{\circ} \mathrm{C}$ is depicted. The droplet having an initial diameter of $1.212 \mathrm{~mm}$ and initial temperature of $61.5^{\circ} \mathrm{C}$ exhibits a slightly steeper slope in the diameter curve, signifying that it evaporates faster than the droplet comprising of $5 \%$ RME, even though it is subjected to an airstream of lower temperature. This observation confirms the previously deduced conclusion that the addition of FAME results in the acceleration of the droplet evaporation.

\section{Conclusion}

A series of simultaneously obtained diameter-temperature measurements regarding pure liquid or multicomponent single droplets, evaporating in a quiescent or convective heated environment have been presented. The produced temporal profiles of droplet diameter and droplet surface temperature may be used for the validation of droplet evaporation computational models. Pure liquid droplets seem to have a rather homogeneous evaporating behaviour, exhibiting almost linearly decreasing "squared diameter" rates, having at the same time abruptly increasing surface temperatures. On the 
other hand, multicomponent fuels (blends of fatty acid methyl ester with industrial diesel oil) show a "smoother" evaporating behaviour, having longer total evaporation times while achieving, on the long term, practically steady-state surface temperatures.

\section{Acknowledgments}

The present study has been financially supported by the E.C. in the frame of an ECproject (Contract No. ENK6-CT-2000-00317).

\section{REFERENCES}

[1] BRENN, G., KASTNER, O., RENSINK, D. and TROPEA, C., "Evaporation and Drying of Multicomponent and Multiphase Droplets in a Tube Levitator", Proceedings of ILASS-Europe99, Toulouse 1999

[2] YARIN, A.L., BRENN, G., KASTNER, O., RENSINK, D. and TROPEA, C., "Evaporation of acoustically levitated droplets", Journal of Fluid Mechanics, 399, 1999, p 151-204

[3] BORMAN, G.L. and RAGLAND, K.W., "Combustion Engineering", McGraw-Hill 1998

[4] SIRIGNANO, W.A., "Fluid Dynamics of Sprays - 1992 Freeman Scholar Lecture", Journal of Fluids Engineering, 115, 1993, p 345-378
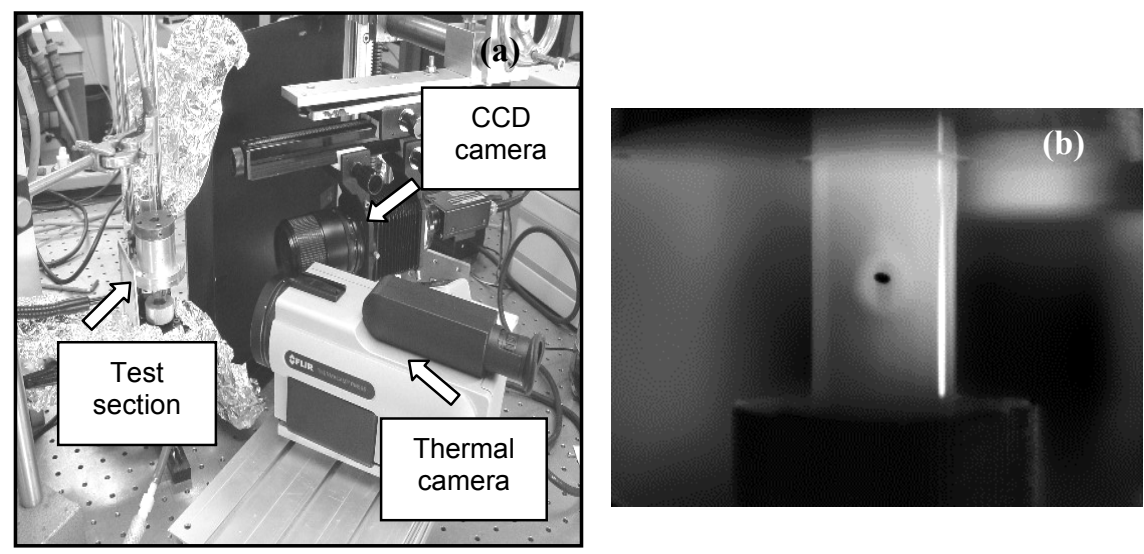

Fig. 1. Experimental test rig: (a) Photograph of the experimental layout, (b) Infra-red photograph of a methanol droplet evaporating at $240 \mathrm{C}$
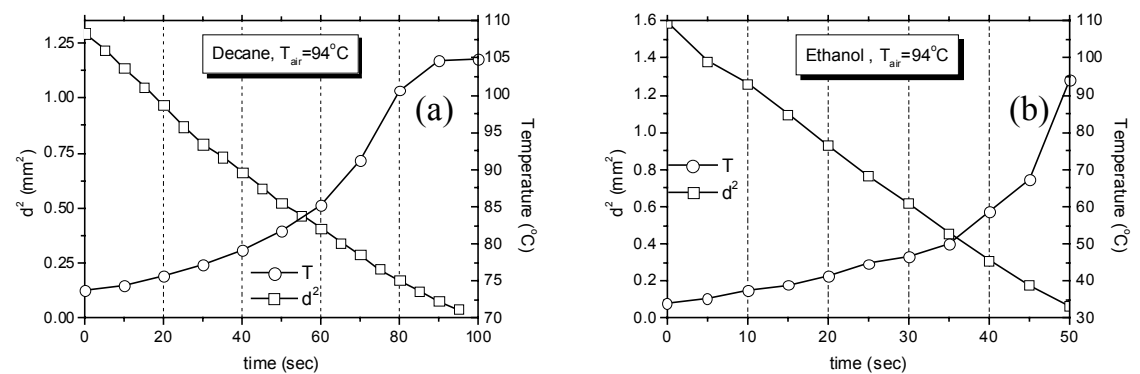

Fig. 2. Temporal evolution of droplet's squared diameter and surface temperature of a droplet subjected to a heated airstream of 94oC. Substance: (a) Decane, (b) Ethanol 

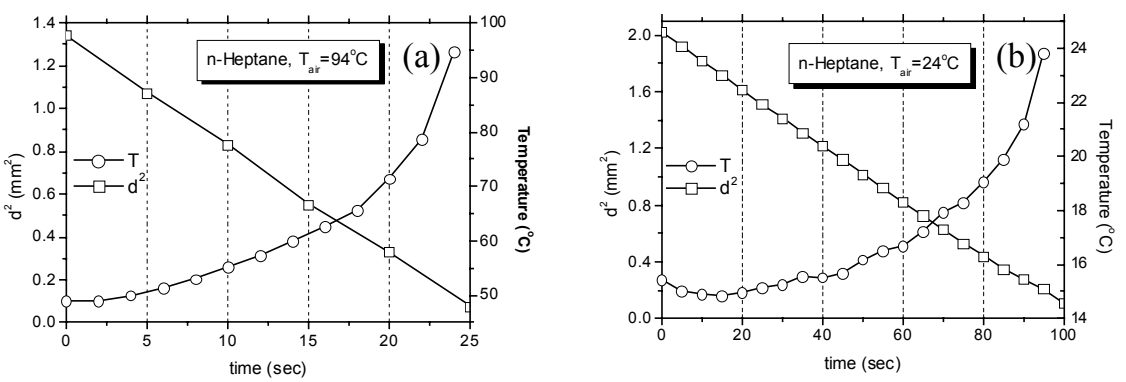

Fig. 3. Temporal evolution of an n-heptane droplet's squared diameter and surface temperature. Heated airstream temperature: (a) 24oC, (b) $940 \mathrm{C}$
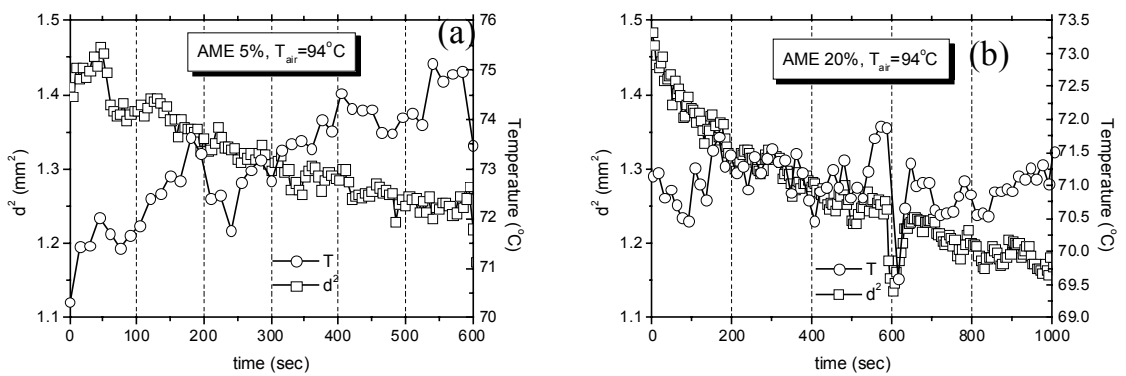

Fig. 4. Temporal evolution of droplet's squared diameter and surface temperature of a droplet subjected to a heated airstream of 94oC. Mixture: (a) Diesel 95\% - AME 5\%, (b) Diesel 80\% - AME 20\%
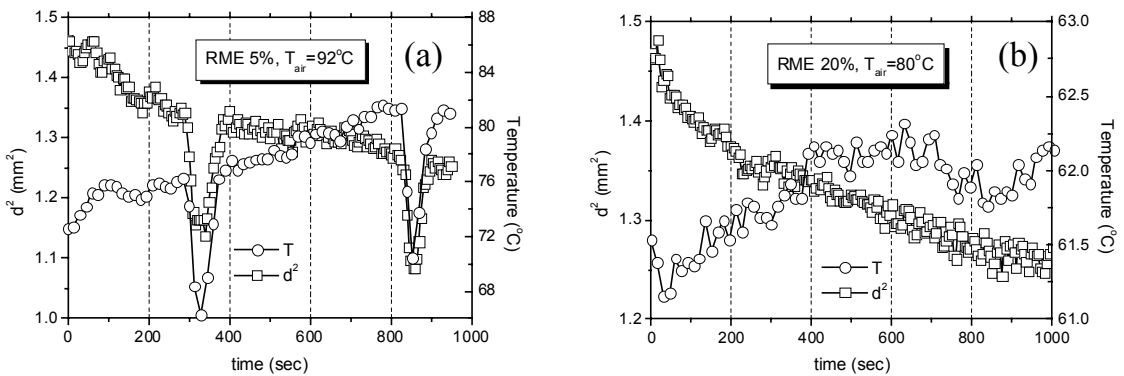

Fig. 5. Temporal evolution of droplet's squared diameter and surface temperature of a droplet subjected to a heated airstream. Mixture: (a) Diesel 95\% - RME 5\%, (b) Diesel 80\% - RME 20\% 